American Journal of Applied Sciences 4 (7): 430-438, 2007

ISSN 1546-9239

(C) 2007 Science Publications

\title{
Comparative Study by Electrochemical Impedance Spectroscopy (EIS) On The Corrosion Resistance of Industrial and Laboratory Zinc Coatings
}

\author{
${ }^{1}$ Y. Hamlaoui, ${ }^{2}$ F . Pedraza and ${ }^{3}$ L. Tifouti \\ ${ }^{1}$ Souk-ahars University Center, PO 1553 Souk-ahars 41000 Algeria \\ ${ }^{2}$ Laboratory of Studies of Materials in Aggressive Media (LEMMA). La Rochelle University 17042 \\ La Rochelle Cedex 1 France \\ ${ }^{3}$ Laboratory of Environment Engineering. Badji Mokhtar University PO 12 El Hadjar Annaba -Algeria
}

\begin{abstract}
In this work, corrosion monitoring of Zn-based coatings is investigated through potentiodynamic and electrochemical impedance spectroscopy (EIS) methods. The first part of the study is devoted to galvanised coatings conventionally manufactured in the industry. The second part focuses on the corrosion resistance of a laboratory-made electrolytic coating. For such purpose, the corrosion behaviour is studied in $\mathrm{NaCl}$ media under various conditions. The results show that EIS allows to establish the interfacial reactions and the dissolution mechanisms occurring in this media, hence to foresee the protection conferred by these coatings. Moreover, the salted media at different concentrations allow to unambiguously assess the coating quality in terms of porosity. However, others corrosive media can reveal the slowest reaction without having appeal to a very low frenquency scanning. Finally, $\mathrm{Zn} / \mathrm{NaCl}$ interface is characterised by a specific equivalent circuit giving a similar impedance response.
\end{abstract}

Keywords: EIS, salt spray chamber, zinc, galvanised steel, corrosion

\section{INTRODUCTION}

Corrosion monitoring is typically carried out using electrochemical methods. Among these, AC impedance has been quoted to provide an upper estimate of the corrosion rate although the Tafel parameters relating corrosion rate and polarisation resistance need to be first evaluated ${ }^{[1]}$. However, electrochemical impedance spectroscopy (EIS) offers the advantage of providing enough insight on the formation and protection mechanisms of a given surface layer ${ }^{[2]}$. Using the EIS method, various sacrificial $\mathrm{Zn}$-based coatings have been evaluated because of their industrial application. For instance, Deslouis et al. ${ }^{[3]}$ determined the kinetics of corrosion of zinc in aerated $\mathrm{Na}_{2} \mathrm{SO}_{4}$ solutions and described a dissolution model. Corrosion was shown to occur essentially at the base of the pores of the coatings and progress of anodic dissolution gave rise to four loops with decreasing frequency ${ }^{[4]}$. Indeed, the compactness of the corrosion products layer developed on zinc needs to be introduced to evaluate its barrier effect ${ }^{[5]}$. Based on this, further insight on $\mathrm{Zn}$ dissolution in sulphate medium has been provided by
Cachet et al. ${ }^{[6]}$ who described a reaction model in which three paths associated to three adsorbed intermediates $\left(\mathrm{Zn}_{\mathrm{ad}}{ }^{\mathrm{I}}, \mathrm{Zn}_{\mathrm{ad}}{ }_{\mathrm{II}}\right.$ and $\left.\mathrm{ZnOH}_{\mathrm{ad}}\right)$ were identified. However, most of the studies are based on laboratory deposited coatings. More recently, the assessment of corrosion behaviour by EIS on industrial Zn-based coatings has been addressed on a $0.5 \mathrm{M}$ sulphate medium ${ }^{[7]}$. Furthermore, the typical preferred crystal orientation of the coatings did not have any significant influence on the corrosion behaviour contrary to what is normally observed in pure zinc ${ }^{[8,9]}$. A more detailed study has been conducted by Pérez et al. ${ }^{[10]}$ by combining accelerated tests in a weathering cyclic chamber with EIS measurements to track the degradation steps of an uncoated galvanised steel. Most of these studies have been carried out in laboratory based coatings. How ever, industrial coatings often show defects of surface, showing itself in the form of pores or relief. Which classify the coatings in term of quality. The presence of chlorides or soluble complex in the defects could initiate the localised corrosion ${ }^{[11]}$. Also, a difference of surface potential can initiate a selective corrosion ${ }^{[12]}$. To the best of our knowledge,

Corresponding Author: Hamlaoui Youcef, Centre University de Souk-ahras. BP1553 Souk-ahras 41000. Algeria 
only Barranco et al. ${ }^{[13,14]}$ have focused on the study of EIS as an analytical tool to continuously monitor the corrosion of various industrial coatings in a $3 \%$ wt $\mathrm{NaCl}$ medium. Few works were dedicated to compare the EIS results of an electroplated coatings with elaborated by hot dipping. Of no more work was the object of study of the influence of the surface porosity (morphology) on EIS diagrams obtained in both cases.

The present work is therefore focused on EIS as a potential analytical tool in industry. The study thus compares the corrosion behaviour of a hot dip industrial coating (HDG)with that of a laboratory electrodeposited coating (EP). To this end, $\mathrm{NaCl}$ solutions have been employed as corrosive media. Further correlation with a gravimetric follow-up and atomic absorption spectrometry is also presented.

\section{MATERIALS AND METHODS}

The substrate is a non alloyed steel S235JR with appropriate $\mathrm{Si}(0.14-0.25 \mathrm{wt} \%)$ and $\mathrm{P}(<0.035 \mathrm{wt} \%)$ contents to allow galvanisation. The galvanized coatings were kindly supplied by Mittal Steel Algeria. The laboratory zinc (electroplated) coatings were obtained from an aereted cyanide -free bath containing between 7-8.5 g/l of $\mathrm{Zn}$ (zinc sulphate) and 125-135 g/l $\mathrm{NaOH}$. The bath température is maintained at $23^{\circ} \mathrm{C}$ under $2 \mathrm{~A} / \mathrm{dm} 2$ of curent density during $32 \mathrm{~min}$. thereafter, the coatings were thoroughly rinsed with deionised water, ethanol, de-ionised water again and then dried in air. Before elctrochemical tests, the samples sheet underwent a typical surface preparation treatment. Morphological characterisation and elemental composition of the coatings was carried out by Scanning Electron Microscopy (SEM) coupled to Energy Dispersive Spectrometry (EDS) in a JEOL $5410 \mathrm{LV}$ apparatus at $20 \mathrm{kV}$.

Samples of $4 \times 4 \times 0.05 \mathrm{~cm}$ were cut from the galvanised plates and most of the surface was protected with an adhesive film to leave a $1 \mathrm{~cm}^{2}$ surface in contact with the corrosive medium. The corrosion tests were carried out at $25^{\circ} \mathrm{C}$ by magnetic stirring the solutions. The corrosive media consisted of $0.1,0.5$ and $1 \mathrm{M} \mathrm{NaCl}$ prepared by analytical chemical product and double deionised water. The electrochemical experimental set-up is composed of a classic three electrodes cell using a platinum grid as counter electrode and a saturated calomel electrode (SCE) as the reference one, the coated samples being connected to the working electrode. The measurements have been carried out using a potentiostat/galvanostat EGG 273A coupled to a frequency response analyser (FRA) EGG 1025. The impedance data were obtained at the corrosion potential
( $\mathrm{E}_{\text {cor }}$ ) between $100 \mathrm{kHz}$ and $100 \mathrm{mHz}$ at $10 \mathrm{mV}$ as the applied sinusoidal perturbation. The Tafel polarisation curves were obtained at a scanning rate of $60 \mathrm{mV} / \mathrm{min}$ between $\pm 250 \mathrm{mV}$ compared to the corrosion potential $\left(\mathrm{E}_{\mathrm{cor}}\right)$. The experiments were monitored using the software EGG M352 and Powersine. EIS results were curve-fitted using Zview's ftengine program. The immersion tests were carried out in $0.1 \mathrm{M} \mathrm{NaCl}$ solution for 3 until 34 days. The $\mathrm{Zn}$ dissolved from the coatings was subsequently determined by atomic absorption spectroscopy (AAS).

\section{RESULTS AND DISCUSSION}

Industrial Zn Coatings: The industrial coatings followed first physicochemical and electrochemical characterisations to verify the specific requirements. Only the coatings showing good continuity and resistance (first appearance of white rust) for at least 32 $\mathrm{H}$ in a salt spray chamber (ASTM B117 standard) were retained for this study. It can be observed in Figure 1 that the coating fully covers the steel substrate with rather coarse grains. Some pores and small bright particles are clearly visible. The surface of the coating seems to be mainly composed of 98 at $\% \mathrm{Zn}$ and 2 at\% $\mathrm{Al}$ but the small bright particles also contain variable amounts of $\mathrm{Pb}$.

The electrochemical results are depicted in Figure 2,3 and 4 . It can be easily observed that the corrosion rate in the aerated $\mathrm{NaCl}$ medium is under cathodic control (oxygen diffusion) regardless of the concentration as indicated by the higher values of Tafel slopes. Moreover, while passing to 0.5 and $1 \mathrm{M} \mathrm{NaCl}$, the cathodic slopes are practically the same ones. This is due to the bricking of the reaction of oxygen reduction. It can be also observed that the corrosion potential, $\mathrm{E}_{\text {corr }}$ stabilises between -1000 and $-1040 \mathrm{mV} / \mathrm{ECS}$. The corrosion current $\left(\mathrm{I}_{\text {corr }}\right)$, calculated by extrapolation of Tafel slops, also increases with increasing the $\mathrm{NaCl}$ concentration. Figure 3 shows the cyclic polarisation curves obtained in $0.1,0.5$ and $1 \mathrm{M} \mathrm{NaCl}$. The specific surface evolution with the increase of the concentration indicates a more important degradation of the coating. However, it appears from the Icor values that the corrosion is increased 10 times for $1 \mathrm{M}$ than in the case of $0.1 \mathrm{M}$. Moreover, the specific surface evolution does not exceed 4 times (table 1). This result could be explained by a corrosion processes developed under the oxide/hydroxide formed layer (at the interface substrate/film), since the porous nature of this layer ${ }^{[7]}$. The displacement of the corrosion potentials according to the concentration confirms this assumption. 

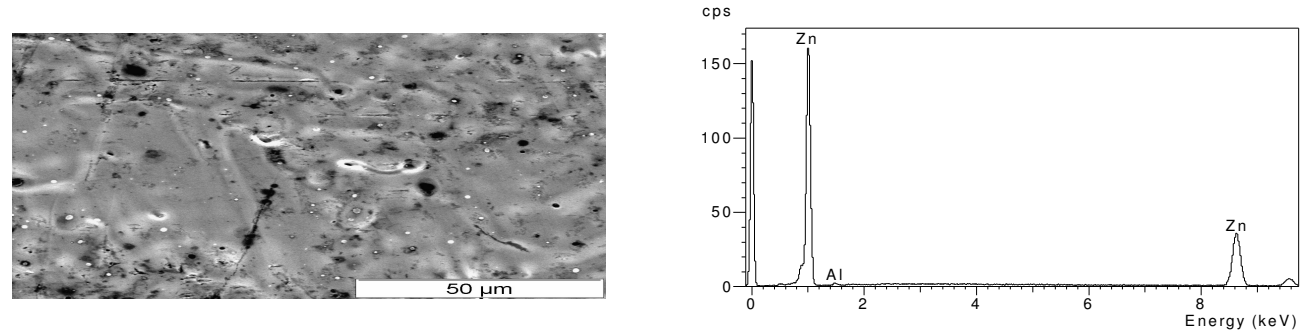

Fig. 1: SEM image and EDS results of industrial Zn coating

Table 1: Electrochemical parameters obtained for the industrial $\mathrm{Zn}$ coatings as a function of $\mathrm{NaCl}$ concentrations and immersion times

\begin{tabular}{|c|c|c|c|c|c|}
\hline \multirow[t]{2}{*}{ testing conditions in $\mathrm{NaCl}$ solution } & \multicolumn{5}{|c|}{ Electrochemical parameters } \\
\hline & $\begin{array}{c}\text { Ecorr } \\
(\mathrm{mV} / \mathrm{SCE})\end{array}$ & $\begin{array}{c}\text { Icorr } \\
\left(\mu \mathrm{A} \cdot \mathrm{cm}^{-2}\right) \\
\end{array}$ & $\begin{array}{c}\text { Vcorr } \\
\left(\mathrm{mm} \cdot \mathrm{y}^{-1}\right)\end{array}$ & $\begin{array}{l}\text { Q } \\
(\mathrm{C}) \\
\end{array}$ & $\begin{array}{c}C \cdot 10^{6} \\
(\mathrm{~S})\end{array}$ \\
\hline $0.1 \mathrm{M}$, Before immersion, $\mathrm{pH}=6.6$ & -1000 & 28 & 0.42 & 8.43 & 0.30 \\
\hline $0.5 \mathrm{M}$, Before immersion, $\mathrm{pH}=6.7$ & -983 & 170 & 2.53 & 13.00 & 0.07 \\
\hline $1 \mathrm{M}$, Before immersion, $\mathrm{pH}=7$ & -1038 & 300 & 4.47 & 37.77 & 0.12 \\
\hline $0.1 \mathrm{M}$ and 13 days of immersion & -1025 & 36 & 0.54 & 12.35 & 0.34 \\
\hline $0.1 \mathrm{M}$ and 20 days of immersion & -996 & 37 & 0.55 & 20.12 & 0.55 \\
\hline $0.1 \mathrm{M} 34$ days of immersion & -994 & 54 & 0.80 & 33.25 & 0.62 \\
\hline
\end{tabular}

Table 2: Electrochemical impedance parameters obtained in different $\mathrm{NaCl}$ concentrations and immersion times of industrial

\begin{tabular}{|c|c|c|c|c|c|c|c|}
\hline $\begin{array}{c}\text { Testing conditions } \\
\mathrm{NaCl} \text { solution }\end{array}$ & $\begin{array}{l}\mathrm{R}_{\mathrm{ct}} \\
(\Omega)\end{array}$ & $\begin{array}{l}\mathrm{F}_{\max } \\
(\mathrm{Hz})\end{array}$ & $\begin{array}{l}\mathrm{C}_{\mathrm{dl}} \\
(\mu \mathrm{F})\end{array}$ & $\alpha$ & $\begin{array}{l}\mathrm{R}^{\prime} \\
(\Omega)\end{array}$ & $\begin{array}{l}\mathrm{F}_{\max }^{\prime} \\
(\mathrm{Hz})\end{array}$ & $\begin{array}{l}\mathrm{C}^{\prime} \\
(\mathrm{F})\end{array}$ \\
\hline $0.1 \mathrm{M}$, Before immersion & 309 & 41.25 & 12 & 0.80 & 271 & 0.14 & 0.004 \\
\hline $0.5 \mathrm{M}$ Before immersion & 110 & 345 & 4 & 0.94 & 39 & 0.20 & 0.020 \\
\hline $1 \mathrm{M}$ Before immersion & 23 & 170 & 40 & 0.68 & 19 & 0.10 & 0.080 \\
\hline 10 days of immersion & 249 & 41.25 & 15.5 & 0.80 & 360 & 0.558 & 0.003 \\
\hline 13 days of immersion & 154 & 28.90 & 35.7 & 0.70 & 78 & 0.100 & 0.002 \\
\hline 20 days of immersion & 146 & 41.25 & 26.4 & 0.72 & 92 & 0.142 & 0.010 \\
\hline 34 days of immersion & 110 & 20.31 & 12 & 0.76 & 33 & 0.290 & 0.016 \\
\hline
\end{tabular}

$\mathrm{R}_{\mathrm{ct}}$ and R' are charge transfer and layer resistance; $\mathrm{C}_{\mathrm{dl}}$ and $\mathrm{C}^{\prime}$ double layer and layer capacity; $\alpha$ is the non linearity coefficient, $\mathrm{F}_{\max }$ is the maximum frequency

Table 3: Electrochemical impedance parameters obtained in different conditions for a fixed immersion time of 0 days of laboratory Zn coatings.

\begin{tabular}{|c|c|c|c|c|c|c|c|}
\hline Testing conditions & $\begin{array}{l}\mathrm{R}_{\mathrm{ct}} \\
(\Omega)\end{array}$ & $\begin{array}{l}f_{\max } \\
(\mathrm{Hz})\end{array}$ & $\mathrm{C}_{\mathrm{dl}}(\mu \mathrm{F})$ & $\alpha$ & $\begin{array}{l}\mathrm{R}^{\prime} \\
(\Omega)\end{array}$ & $\begin{array}{l}\mathrm{F}_{\text {max }}^{\prime} \\
(\mathrm{Hz})\end{array}$ & $\begin{array}{l}\mathrm{C}^{\prime} \\
(\mathrm{F})\end{array}$ \\
\hline $0.1 \mathrm{M}-\mathrm{pH}$ solution 6.6 & 195 & 127 & 6.42 & 0.75 & -58 & 0.3 & -0.027 \\
\hline $0.5 \mathrm{M}-\mathrm{pH}$ solution 6.6 & 153 & 127 & 8.20 & 0.67 & -10 & 0.3 & -0.058 \\
\hline $1 \mathrm{M}-\mathrm{pH}$ solution $(6.7)$ & 108 & 115 & 12.80 & 0.71 & -18 & 9.0 & -0.0009 \\
\hline $0.1 \mathrm{M}-\mathrm{pH}=5$ & 180 & 127 & 7.00 & 0.78 & -58 & 0.3 & -0.027 \\
\hline $0.1 \mathrm{M}-\mathrm{pH}=10$ & 179 & 204 & 4.00 & 0.79 & -66 & 0.3 & -0.024 \\
\hline $0.1 \mathrm{M}-\mathrm{pH}=11$ & 142 & 127 & 9.00 & 0.85 & -85 & 0.5 & -0.019 \\
\hline $1 \mathrm{M}-\mathrm{pH} 6.70$ de-aerated & 270 & 7 & 78.40 & 0.70 & 150 & 1.1 & 0.002 \\
\hline
\end{tabular}



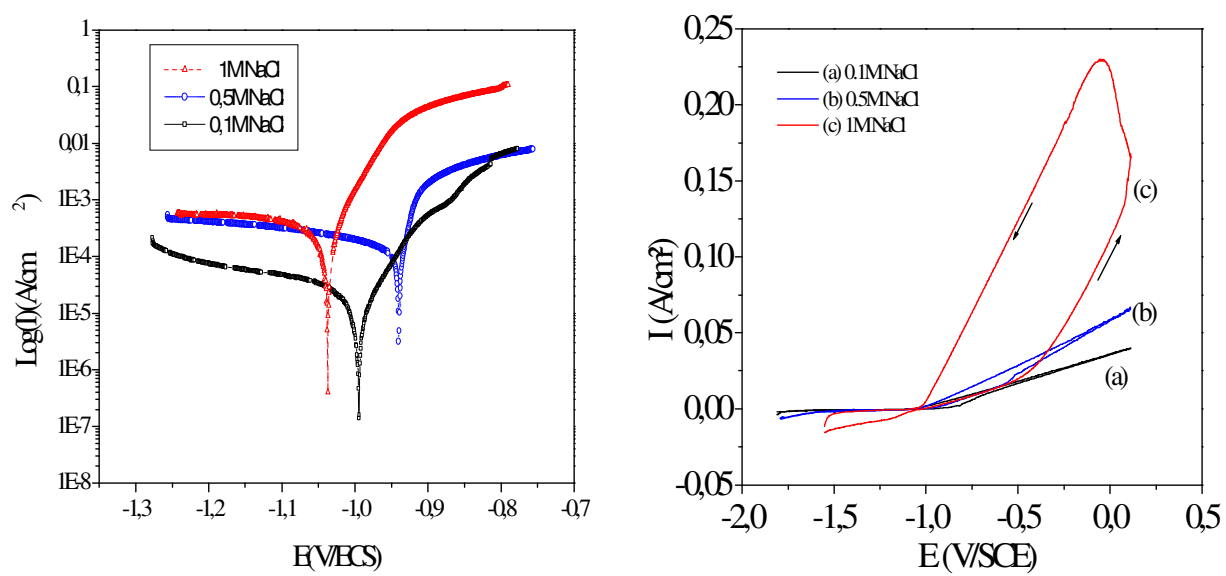

Fig 2: polarisation curves obtained on industrial Zn Fig 3: Cyclic polarization curves obtained on coatings in $\mathrm{NaCL}$ solution industrial $\mathrm{Zn}$ coatings in $\mathrm{NaCl}$ solution
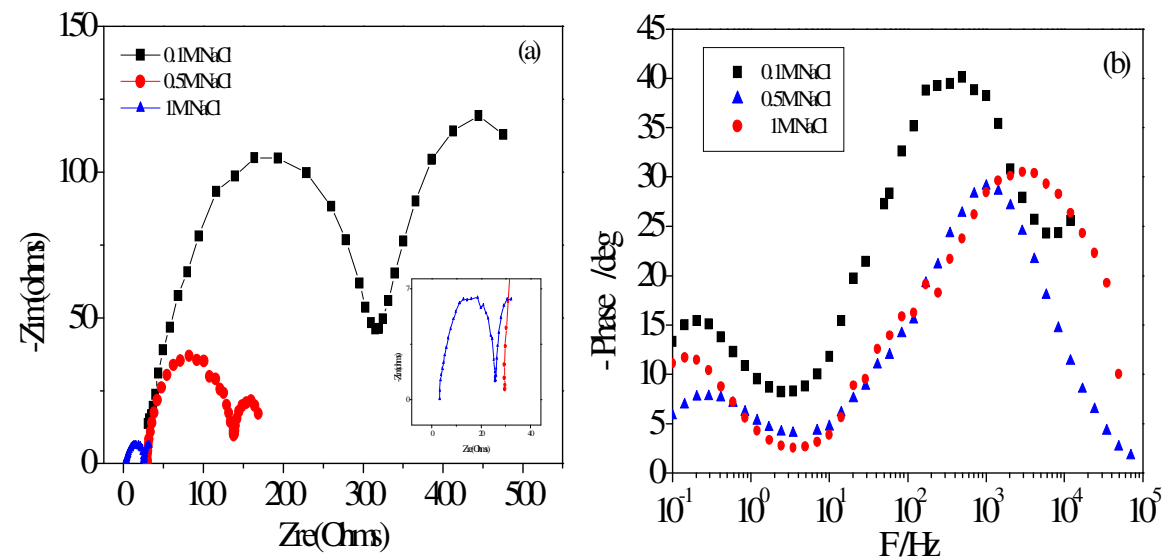

Fig 4: EIS Nyquist a) and Bode b) diagrams obtained on industrial coatings in $\mathrm{NaCl}$ solution
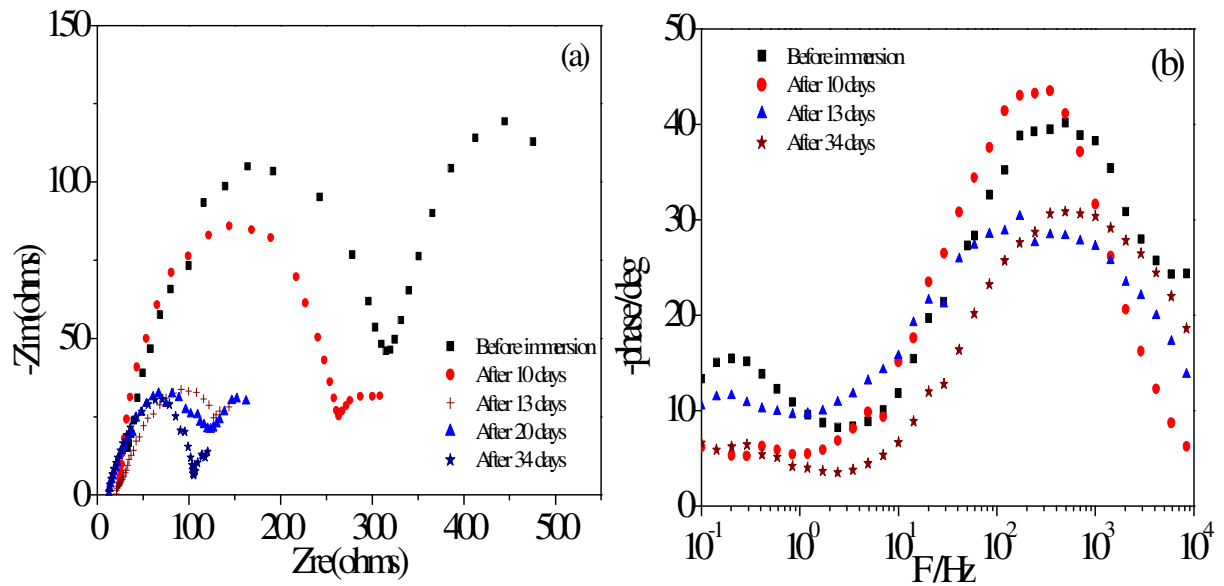

Fig 5: EIS Nysuist a) and Bode b) diagrams obtained on industrial coatings at different time immersion in $0.1 \mathrm{M} \mathrm{NaCl}$ solution 
It can be observed in Table 2 that by increasing the $\mathrm{NaCl}$ concentration the charge transfer resistance decreases and therefor more corrosion occurs. The double-layer capacity values do not seem to follow the trend of the resistance values, which lead us to believe that a dispersion of the relaxation time occurs. Ferreira et all ${ }^{[15]}$ obtained two time constant $(\tau)$ for a hot galvanised steel in $0.05 \mathrm{M} \mathrm{NaCl}$. The first one appear at intermediary frequencies followed by another at low frequency (LF). The latter was related to the oxide layer formed.

constant well distinguished at $100 \mathrm{~Hz}$ and the other between 1 and $0.1 \mathrm{~Hz}$. This result suggest that the concentration doesn't affect the number of time constant. In our case, the diagrams obtained at different $\mathrm{NaCl}$ concentrations show two time

Becaus of the week degradation of the coating observed for the lowest $\mathrm{NaCl}$ concentration, a series of tests was carried out in stirred $0.1 \mathrm{M}$ solutions to evaluate the evolution of the galvanised coatings with immersion time . As suggested by Table 2, three stages occurs. For the shortest immersion times, reduction of the anodic slope and shifting of $\mathrm{E}_{\text {corr }}$ towards more cathodic domains occurs. This is in agreement with previous works which showed that the corrosion products layer developed during the first immersion times afforded limited protection ${ }^{[2]}$. The second stage takes place between 13 and 20 days in which the corrosion current $\left(\mathrm{I}_{\text {corr }}\right)$ tends to stabilise and finally increases after 34 days of immersion in $0.1 \mathrm{M} \mathrm{NaCl}$. This feature can be ascribed to desorption of the corrosion products from the surface or to some charge transfer occurring through the porous layer of corrosion products. This is confirmed from the evolution of the compactness $(\mathrm{C}=$ $\mathrm{Q} / \mathrm{I}_{\text {corr }}$ ) of the corrosion products layer. The increase of the compactness might certainly derive from enhanced dissolution reactions at the electrolyte/metal interface which in turn modifies the $\mathrm{pH}$ values from 6.6 to 7.6. at the beginning and the end of the test, respectively. The increase of $\mathrm{pH}$ can be related to the oxygen reduction which produces hydroxide groups thus favouring the stabilisation of the corrosion products.

$$
\mathrm{O}_{2}+2 \mathrm{H}_{2} \mathrm{O}+4 \mathrm{e}^{-} \longrightarrow 4 \mathrm{OH}^{-}
$$

Indeed, because of their weak solubility, the corrosion products precipitate at the surface of the electrode building up an increasingly compact layer. This layer is typically composed of $\mathrm{ZnO}, \mathrm{Zn}(\mathrm{OH})_{2}$, $\mathrm{Zn}_{5}(\mathrm{OH})_{8} \mathrm{Cl}_{2} \cdot \mathrm{H}_{2} \mathrm{O}$ (simonkolleite) or their mixtures but Barranco et al. ${ }^{[13]}$ have quoted $\mathrm{ZnO}$ as the major compound of this layer.
Impedance diagrams of the $\mathrm{Zn}$ coatings at their corrosion potential have also been obtained at different immersion times (Figure 5, Table 2). For the shortest immersion times, a capacitive loop at $\mathrm{HF}$ and the beginning of a LF loop are well defined. The HF loop has circular arc shape thus underlining the non uniformity of the surface of the electrode (dispersion of the time constant). Such non uniformity can be for instance related to slight modifications of the electrolyte at the diffusion layer and/or to the oxide layer being formed by adsorption as well as from heterogeneities within at the surface of the galvanised coating ${ }^{[3]}$. In agreement with Nyquist diagrams, the Bode plots show two time-constants at around 100 and $0.1 \mathrm{~Hz}$ before immersion. However, with the increase of the immersion time a progressive disappearance of the second time constant occurs. The $\mathrm{R}_{\mathrm{ct}}$ valeus shows that the resistance decreases in two distinct periods. Between 0 and 13 days, the resistance loses about one half of its initial value due to a rapid degradation of the coating, then tends to level off. Such stabilisation may be due to the build-up of a stable layer of corrosion products. Conversely, the corrosion current obtained as a function of immersion time shown three distinct intervals. The first one corresponds to an increase between 0 and 13 days followed by a slight stabilisation between 13 and 20 days finishing up with a significant acceleration towards 34 days of immersion. The difference observed between the two results (DC and AC methods) is explained by the fact that the first method is useful has to calculates a uniform corrosion current whereas the second one considers only the faradic process.

Flattening of the semicircles provides an indication of the surface roughness of a material ${ }^{[1,16]}$. A perfectly smooth surface corresponds to a perfect semicircle and the sphericity decreases with increasing roughness ${ }^{[1]}$. According to this, it can be concluded that as $\mathrm{Zn}$ dissolves in the $0.1 \mathrm{M} \mathrm{NaCl}$, the surface becomes progressively more uniform.

In order to confirm the above discussed electrochemical results, a series of real time immersion tests have been carried out. The corrosion rate determined after 13 days on immersion in $0.1 \mathrm{M} \mathrm{NaCl}$ by electrochemical and AAS method was 0.54 and $0.50 \mathrm{~mm} /$ year respectively. Similar results are observed when depicting the electrochemical results except for 0 days because of the immediateness of the electrochemical measurement. Although, the trials in real time give lower corrosion rates values than those obtained through electrochemical methods ${ }^{[3,11]}$. Moreover, the potential of the $\mathrm{Zn} / \mathrm{Zn}^{2+}$ reaction determined from the solubility 
products of the corrosion species is close to $-1.030 \mathrm{~V}$, which is rather similar to the corrosion potential measured for the different testing conditions. Therefore, the application of the Stern-Geary approximation should not be employed as it has been concluded that the difference between the corrosion potential and the reversible potential should be more than $13 \mathrm{mV}[11,17]$. Nevertheless, only slight differences are found when comparing the two methods.

EIS Spectra obtained were simulated with equivalent circuit shown in Figure 7. The circuit employed allows the identification of both solution resistance (Rs) and charge transfer resistance (Rct). It is important to mention that the double layer capacitance value is affected by imperfection of the surface, and that this effect is simulated via a constant phase element (CPE) with $\alpha$ represents a parameter describing the width of the material property distribution. The different tables obtained (table 2 and 4) show the representative parameter values of the best fit to experimental data and allow to describe the overall impedance through equation (2).

$$
\begin{aligned}
& Z(w)=R_{s}+\frac{R_{c t}}{\left(j w R_{c t} C_{d l}\right)^{\alpha 1}+\frac{1}{1+Z_{2} / R_{c t}}} \\
& Z_{2}(w)=\frac{R^{\prime}}{\left(j w R^{\prime} C^{\prime}\right)^{\alpha 2}+1}
\end{aligned}
$$

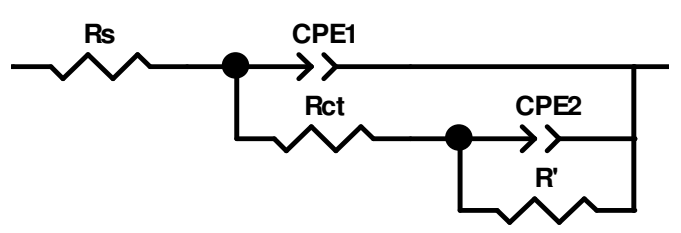

Fig. 7: Equivalent circuit representing the interface : Substrate / $\mathrm{NaCl}$ solution

in which $\mathrm{R}_{\mathrm{s}}$ : Resistance of the solution. $\mathrm{CPE}_{1}$ : Constant phase element characterised by : $\mathrm{C}_{\mathrm{dl}}$ : Double layer capacity (non uniform), $\alpha$ : non linearity coefficient, $\mathrm{R}_{\mathrm{ct}}$ : Charge transfer resistance. $\mathrm{CPE}_{2}$ : constant Phase element characterised by: C': Capacity of the oxide / hydroxide layer and $\alpha^{\prime}$ : non linearity coefficient, R' : Resistance of the layer

3.2.- Laboratory coatings

With aim of approaching the conditions of hot galvanisation, electrodeposition was carried out in alkaline bath without additives and in experimental conditions cited in
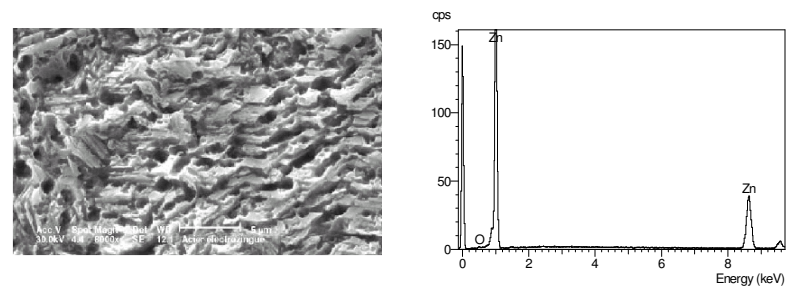

Fig. 8: SEM image and EDS results of the Laboratory coating

The coating obtained by electrodeposition was homogeneous adherent and without imperfection with a thickness of $10 \mu \mathrm{m}$. With an aim of approaching the industrial coating surface, our coating underwent an attack for few seconds by $\mathrm{HCl}$ at weak concentration $^{[18,19]}$. For this purpose, the surface (figure 8) shows a state of porosity similar to that observed on industrial coating. The impedance diagram of the laboratory coatings immersed in a $0.1 \mathrm{M} \mathrm{NaCl}$ solution shows two relaxation times [Figure 9]. The first one corresponds to a capacitive loop at HF, flattened and deformed in its left side, typical of a charge transfer whereas the second one is ascribed to an inductive loop in the capacitive plane. While passing to $0.5 \mathrm{M}$ the initiation of a new loop is observed with difficulty, this becomes clear at $1 \mathrm{M}$. For this purpose, diagram will be composed of a capacitive loop between two inductive loops. In the literature, only one reactional model was proposed to describe the process of dissolution of pure $\mathrm{Zn}$, that is in $\mathrm{NaCl}^{[4,6 \text { and } 7]}$ or in $\mathrm{Na}_{2} \mathrm{SO}_{4}{ }^{[3]}$. The model highlights two processes in parallel with the presence of two adsorbed species. Thus, diagrams EIS comprise at LF three relaxation processes. In the present study, the three relaxation processes are revealed only with concentration equals $1 \mathrm{M}$. according to ${ }^{[4]}$ the deformation of the left part of the capacitive loop HF is related to the existence of pores on the surface of the electrode.

Moreover, the anodic reactions of dissolution does not appear only at their base i.e. their inner surface is regarded as inactive. For this purpose, the 4 relaxation processes observed in diagrams EIS are allotted to : the HF capacitive loop is related to the charge transfer, HF inductive loop is related to the presence of $\mathrm{Zn}^{\mathrm{I}}$ (intermediate species), the LF capacitive loop which is related to the precipitation and migration of $\mathrm{Zn}^{\mathrm{II}}$ by diffusion and the LF inductive loop is related to disappearance of oxide layer with time. 

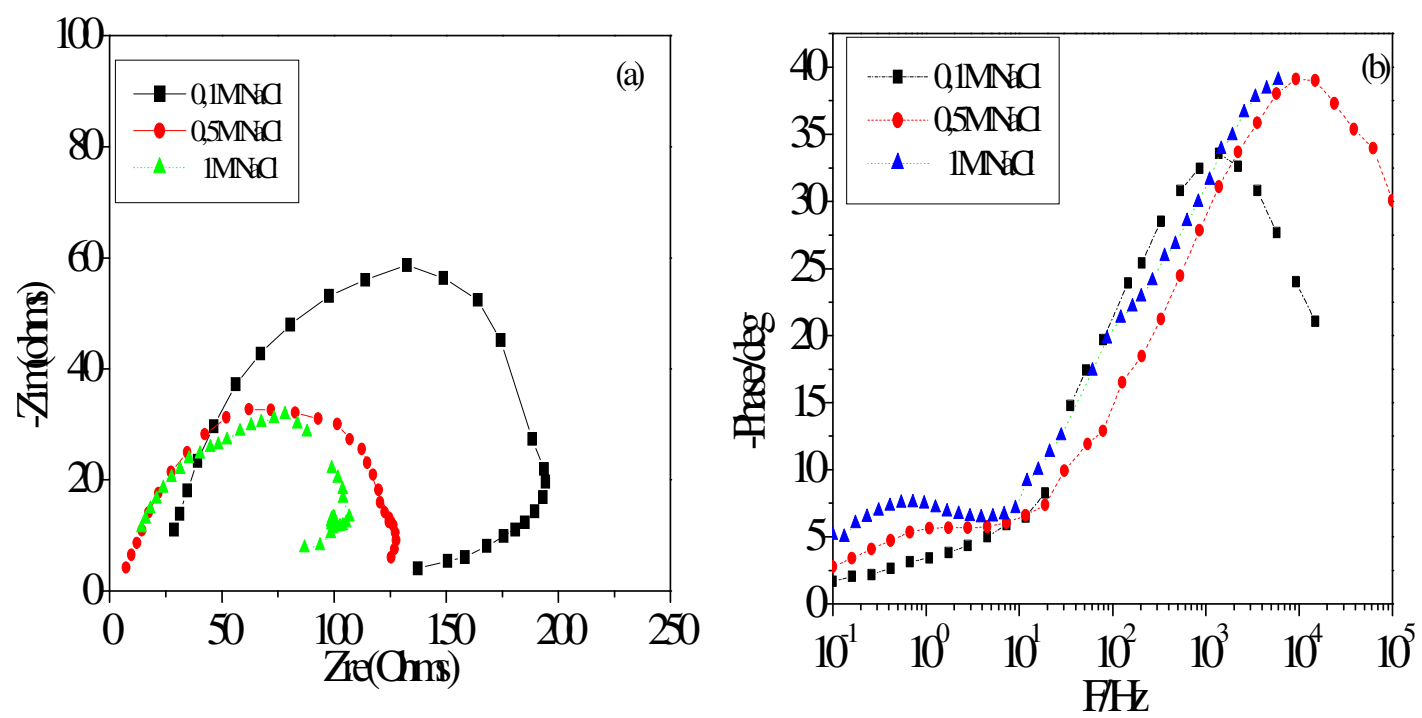

Fig . 9: EIS Nyquist and Bode spectra obtained on laboratory in $\mathrm{NaCl}$ solution at different concentrations

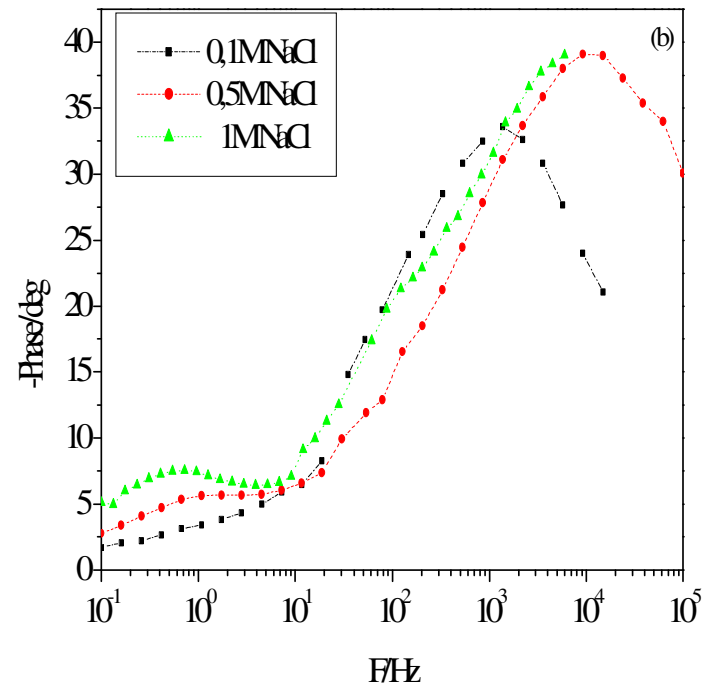

Fig 10: EIS spectra obtained on laboratory $\mathrm{Zn}$ coatings in $0.1 \mathrm{M} \mathrm{NaCl}$ at different $\mathrm{pH}$

In the case of the diagram obtained in $\mathrm{NaCl} 0.1 \mathrm{M}$ at different $\mathrm{pH}$, the absence of the two relaxation processes is due primarily to two phenomena: Firstly, the formation and transformation of the $\mathrm{Zn}^{\mathrm{I}}$ species (intermediary species) is fast and consequently it will occupy a weak surface coverage $\left(\left(\theta_{1}\right)\right.$ is weak)) and/or the oxide /hydroxide layer formed on $\mathrm{Zn}$ is chemically stable (temporary passivation) what returns its speed of detachment weak and by consequently a braking of the fourth relaxation process. The weak appearance of an inductive loop at LF in diagram EIS obtained in $0.5 \mathrm{M}$

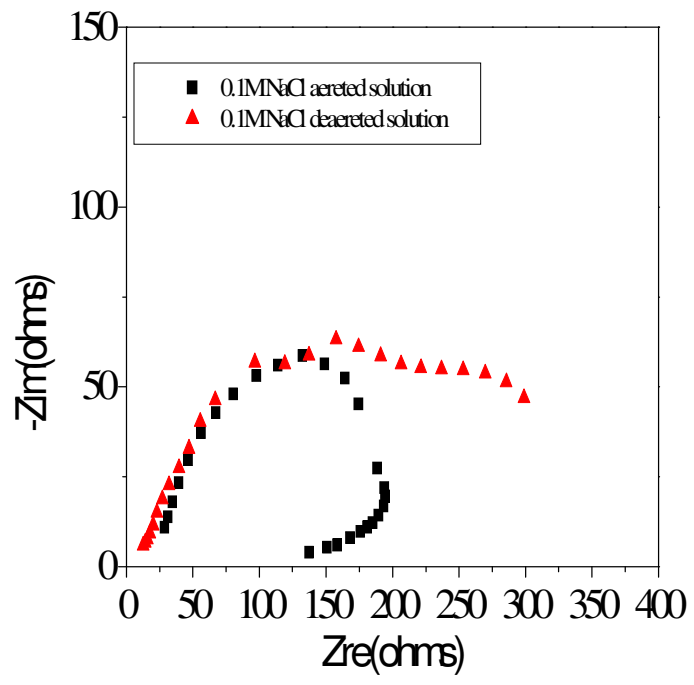

Fig. 11 : EIS spectra obtained on laboratory Zn coatings in aerated and de-aerated $\mathrm{NaCl} 0,1 \mathrm{M}$

confirms these assumptions. The low values of $\mathrm{C}_{\mathrm{dl}}$ and the stability of the Rct values obtained at $\mathrm{pH}$ between (5-10), indicate the establishment of a chemical quasiequilibrium of the corrosion products (temporary passivation) in agreement with the Pourbaix diagrams ${ }^{20]}$. This layer starts to lose its stability at $\mathrm{pH}=11$.

By increasing the $\mathrm{NaCl}$ concentration from 0.1 to 0.5 and $1 \mathrm{M}$, the transfer resistance loses 21 and $44 \%$ of its value respectively. On the contrary, the $\mathrm{R}_{\mathrm{ct}} \mathrm{xI}_{\text {cor }}$ product remain practically constant $(20 \mathrm{mV})$. 
With aim to see the influence of oxygen, a test was carried out in $0,1 \mathrm{M} \mathrm{NaCl}$ deaerated solution figure 11 . The oxygen concentration, measured by standard oxymeter Z621 consort, in the aerated and deaerated solution is between 8 to $10 \mathrm{ppm}$ and 1 to $2 \mathrm{ppm}$ respectively. Diagram EIS obtained in deaerated solution presents two capacitive loops overlapped. In the same way, Bode diagram, shows two very close time-constants. This behaviour can be explained by a fast filling of the pores by corrosion products made up of $\mathrm{Zn}$ hydroxide, which are converted into oxide according to:

$\mathrm{Zn}^{+2}+2 \mathrm{OH}^{-} \longrightarrow \mathrm{Zn}(\mathrm{OH})_{2} \longrightarrow \mathrm{ZnO}+\mathrm{H}_{2} \mathrm{O}$

In addition, the decrease in the quantity of oxygen in the medium slowed down the cathodic reaction (oxygen reduction) and slightly decreases the $\mathrm{pH}$ on the surface of the electrode. With an aim to have an idea on the variation of the $\mathrm{pH}$ near the electrode in both cases of oxygenation, we suppose that only the cathodic reaction is oxygen reduction according to equation 1: At equilibrium state :

$i_{c}=\frac{\left[\mathrm{O}_{2}\right]_{b} n D_{\mathrm{O}_{2}} F}{\delta}=\frac{\left(\left[\mathrm{OH}^{-}\right]_{s}-\left[O \mathrm{H}^{-}\right]_{b}\right) D_{\mathrm{OH}^{-}} F}{\delta}$

In this expression $\mathrm{D}_{\mathrm{O} 2}$ and $\mathrm{D}_{\mathrm{OH}-}$ are diffusion coefficient of oxygen and hydroxide respectively. $\delta$ is the thickness of Nernet layer, $\left[\mathrm{O}_{2}\right]_{\mathrm{b}}$ and $\left[\mathrm{OH}^{-}\right]_{\mathrm{b}}$ are the concentrations of oxygen and hydroxide in bulk solution respectively, $\left[\mathrm{OH}^{-}\right]_{\mathrm{S}}$ is the concentration of hydroxide at surface electrode, $\mathrm{F}$ is the faraday number, $\mathrm{n}$ is the number of exchanged electron ( it can be 2 or 4 ). Sight that the value of $[\mathrm{OH}-]_{b}$ is very weak, we Considers that $[\mathrm{OH}-]_{b}$ $=0$. Making the replacement in equation above, we obtain for $\mathrm{n}=2$ a $\mathrm{pH}$ value of 10.35 and 11.28 for deaerated and aerated media respectively. According to the values illustrated in table 7 and 8 , we deduces that the coating in the deaerated solution (local $\mathrm{pH}=10.35$ ) resists better against corrosion. Elimination of oxygen from the solution does seem to affect the shape of the curves and the resistance increases to $270 \Omega / \mathrm{cm}^{2}$. The oxygen reduction seems then dependent of the relaxation time and influences to overall current. The electrochemical parameters obtained from the stationary curves in a $0.1 \mathrm{M} \mathrm{NaCl}$ solution seem to be in agreement with the results obtained from the frequency technique. At $\mathrm{pH} 9$ and 10 the corrosion products are relatively stable and behave as a protective layer. Alcalinisation of the solution brings about dissolution of the corrosion products, which in turn increases the corrosion current. Therefore, the total impedance can be given through equation (5):

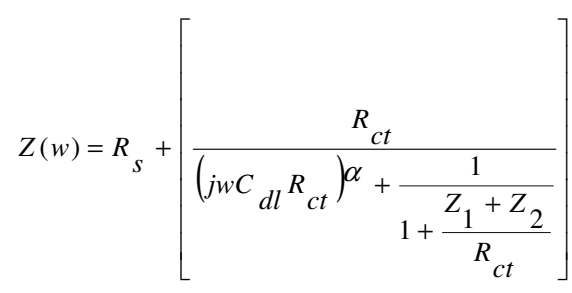

$$
\text { with } \mathrm{Z}_{1}=\frac{\mathrm{R}^{\prime}}{1+\left(\mathrm{jw} \mathbf{C}^{\prime} \mathbf{R}^{\prime}\right)^{\alpha_{1}}} \text { and } \mathrm{Z}_{2}=\frac{\mathbf{R}^{\prime \prime}}{1+\left(\mathrm{jw} \mathbf{C}^{\prime \prime} \mathbf{R}^{\prime \prime}\right)^{\alpha_{2}}}
$$

When the $\mathrm{NaCl}$ concentration is of $0.1 \mathrm{M}, \mathrm{Z}_{2}=0$. On the other hand, for $1 \mathrm{M}$, the parameters of the last inductive loop are : $\mathrm{R}^{\prime \prime}=-32 \mathrm{ohms}$ and $\mathrm{C}^{\prime}=-0.02 \mathrm{~F}$ at $\mathrm{F}=0.233 \mathrm{~Hz}$.

\section{CONCLUSIONS}

The characterization of surface of the two samples by MEB highlighted a state of apparent porosity but nondistinguishable between deep or only superficial. Deep pores can blame the effectiveness of the coating against corrosion. Using EIS method coupled with other methods, we could shown that hot galvanized steel presents only a state of superficial porosity. On the other hand, the electroplated samples presented a state of deep porosity but which do not reach basic steel. According to the shape of the diagrams obtained, the pores are active in their base and inactive on their interior surface. The reactional mechanism of dissolution of pure $\mathrm{Zn}$ in $\mathrm{NaCl}$ and $\mathrm{Na}_{2} \mathrm{SO}_{4}$ proposed by [Delsouis and Cachet] finds its application on galvanized steel only in $\mathrm{NaCl} \geq 1 \mathrm{M}$. on the other hand, at lower concentration, the diagrams of impedance obtained shows only one relaxation process at LF. Moreover the electrochemical effectiveness of electroplated coating, evaluated by linear, cyclic polarization and EIS is better than that of Hot diped steel. The $\mathrm{NaCl}$ solution with weak concentration $(<1 \mathrm{M})$ does not constitute a likely medium to reveal (to initiate) the weakest processes and consequently to confirm the porous state of a electroplated steel. The nucleation and initiation of slow reactions require a very low frequency sweep with long response times, which may modify the surface state of the electrode. For this purpose, the $\mathrm{NaCl} 1 \mathrm{M}$ solution can allow to appreciate the surface quality of the coating. However, others corrosive media can reveal the slowest reaction 
without having appeal to a very low frenquency scanning.

\section{REFERENCES}

1. D.E. Williams, J. Asher, Measurement of low corrosion rates, 1984. Comparison of A.C. impedance and thin layer activation methods. Corrosion Science, 24(3) :185-196

2. R.L. Zeller, R.F. Savinelle, 1986. Interpretation of A.C. impedance response of chromated electrogalvanized steel. Corrosion Science, 26(5):389-399

3. C. Deslouis, M. Duprat, Chr. Tournillon, 1989. The kinetics of zinc dissolution in aerated sodium sulphate solutions. Corrosion Science, 29(1):13-30

4. C. Cachet, B. Saidani, R. Wiart, 1992. The behavior of Zinc electrode in alkaline electrolytes. J. Electrochem. Soc., 139 (3):644-653

5. I. Suzuki, 1985. The behavior of corrosion products on zinc in sodium chloride solution. Corrosion Science, 25(11) :1029-1034

6. C. Cachet, F. Ganne, G. Maurin, J. Petitjean, V. Vivier, R. Wiart, 2001. EIS investigation of zinc dissolution in aerated sulfate medium. Part I: bulk zinc. Electrochem. Acta., 47 : 509-518

7. C. Cachet, F. Ganne, S. Joiret, G. Maurin, J. Petitjean, V. Vivier, R. Wiart, 2002. EIS investigation of zinc dissolution in aerated sulphate medium. Part II: zinc coatings. Electrochem. Acta, 47: 3409-3422

8. H. Park, J.A. Spuznar, 1998. The role of texture and morphology in optimizing the corrosion resistance of zinc-based coatings. Corrosion Science, $40: 525-545$

9. P.R. Seré, J.D. Culcasi, C.I. Elsener, A.R. Di Sarli, 1999. Relationship between texture and corrosion resistance in hot dip galvanised steel. Surface Coatings Technology, $122: 143-149$

10. C. Pérez, A. Collazo, M. Izquierdo, P. Merino, X.R. Nóvoa, 2002. Comparative study between galvanised steel and three duplex systems submitted to a weathering cyclic test. Corrosion Science, 44 : 481-500
11. S. Peulon, D. Lincot, 1998. Mechanistic study of cathodic electrodeposition of zinc oxide and zinc hydroxychloride films from oxygenated aqueous zinc chloride solutions. J. Electrochem. Soc, 145 :864

12. A. Amedeh, B. Pahlevani, S. Heshmati, 2002. Effects of rare earth metal addition on surface morphology and corrosion resistance of hot-dipped zinc coatings, Corrosion science. 44 :2321-2331

13. V. Barranco, S. Feliu Jr., S. Feliu, 2004. EIS study of the corrosion behaviour of zinc-based coatings on steel in quiescent $3 \% \mathrm{NaCl}$ solution. Part 1: directly exposed coatings. Corrosion Science., 46 :2203-2220

14. V. Barranco, S. Feliu Jr., S. Feliu, 2004. EIS study of the corrosion behaviour of zinc-based coatings on steel in quiescent 3\% $\mathrm{NaCl}$ solution. Part 2: coatings covered with an inhibitor-containing lacquer. Corrosion Science., 46 :2221-2240

15. M. G. S. Ferreira, R. G. duarte, M. F. Montemor, 2004. Silanes and rare earth salts as chromate replacers for galvanised steel. Electrochimica acta, 49:2927-2935

16. C. Cachet, U. Ströder, R. Wiart, 1982. The kinetics of zinc electrode in alkaline zincate electrolytes. Electrochemica Acta., 27 (7) :903-908

17. F. Mansfeld, K.B. Oldham, 1971. The effect of of temperature on the corrosion rate of zinc of differents purity in 6M KNO3. Corrosion Science., 11: 557-559

18. E. Almeida, M. Morcillo, B. Rosales, 2000. Atmospheric corrosion of zinc Part 2: Marine atmospheres. British Corrosion Journal., 35 (4) :289-296

19. I. Odnevall, C. Leygraf, 1993. Formation of $\mathrm{NaZn}_{4} \mathrm{Cl}(\mathrm{OH})_{6} \mathrm{SO}_{4} 6 \mathrm{H}_{2} \mathrm{O}$ in a marine atmosphere. Corrosion Science., 34 (8) :1213-1229

20. M. Pourbaix, 1963. Atlas d'équilibres électrochimiques, Gauthier-Villars, Paris. 